\title{
Como se deve ler a história? Leitura e legitimação na historiografia moderna*
}

\author{
How history should be read? \\ Reading and legitimacy in modern historiography ${ }^{* \star}$
}

FERNANDO NICOLAZZI
Doutor em História/UFRGS
Departamento de História/ICHS Rua do Seminário, s/n
Mariana/MG, 35.420-000
f.nicolazzi@hotmail.com

RESUMO Este ensaio estuda alguns textos ocupados com a temática da leitura da história na época moderna, desde o século XVII até o século XX. Partindo da hipótese de que a legitimidade do saber histórico reside não apenas na prática da escrita realizada pelos historiadores, mas igualmente na sua abordagem feita pelos leitores, a partir de um "pacto de leitura" que o texto historiográfico estabelece, diversas modalidades de leitura da história são apontadas, indicando os diferentes horizontes de expectativa que constituem a historiografia moderna.

Palavras-Chave Historiografia moderna, leitura da História, legitimidade do discurso histórico

ABSTRACT This essay studies some works written about the reading of history in the modern period, from the $18^{\text {th }}$ to the $20^{\text {th }}$ century. Considering,

* Artigo recebido em 29/09/09. Aprovado em: 19/03/2010.

** Uma versão preliminar deste ensaio foi apresentado oralmente em julho de 2009, no GT Teoria da História e Historiografia/ANPUH-RS. Agradeço aos coordenadores, Hugo Hruby e Luciana Boeira, a calorosa recepção, e aos demais colegas a oportunidade do debate. Os estudos de que resultaram este texto foram financiados pela Capes. 
hypothetically, that the legitimacy of the historical knowledge lies not only upon the practice of writing made by historians, but also upon the approach by its readers, as a "reading pact" established in the historiographical text, some reading modalities are noticed, indicating the different expectations which constitute modern historiography.

Keywords Modern historiography, reading of History, historical discourse legitimacy

I.

Todos têm fantasias. As minhas são devaneios históricos (...). Eu me afundo em minha poltrona, nas mãos um livro pesado que vai ficando cada vez mais pesado, e me entrego a um cochilo. Então acordo por um beijo. Às vezes é o beijo da morte, às vezes o beijo do amor, um pequeno amor, amor perdido entre as paixões do passado: le baiser de Lamourette.

A significativa imagem elaborada por Robert Darnton, um historiador que se pode chamar de profissional, não deixa de trazer em si as marcas fortes do senso comum: a idéia de que os livros de história podem encaminhar o espírito (na falta de palavra melhor) para estados alterados de consciência, os quais, por sua vez, teriam a capacidade de colocar o leitor em contato direto com a "realidade" lida. Darnton explora ainda mais aquela imagem, sugerindo que "o contato com o passado altera o sentido do que pode ser conhecido. Estamos sempre nos ombreando com mistérios - não simplesmente a ignorância (fenômeno familiar), mas a insondável estranheza da vida entre os mortos. Os historiadores voltam desse mundo como missionários que partiam para conquistar culturas estrangeiras e agora retornam convertidos, rendidos à alteridade dos outros.

De tudo isso emerge, para o historiador norte-americano, um problema capital para a escrita da história. Nas suas palavras, "como o velho marinheiro, falamos com os mortos, porém temos dificuldade em nos fazer ouvir entre os vivos. Para eles, somos maçantes". Assim, Darnton formula uma indagação forte:

Nós, profissionais da história, não podemos fazer nada para ter contato com o leitor médio? Será que nos emparedamos por trás de uma barreira de monografias e cortamos o diálogo com os cidadãos comuns curiosos a respeito do passado? (...) Escrevemos de uma maneira que nos legitima aos olhos dos profissionais e torna nosso trabalho inacessível a qualquer outra pessoa. ${ }^{1}$

1 DARNTON, Robert. Introdução. In: O beijo de Lamourette. Mídia, cultura e revolução. São Paulo: Companhia das Letras, 1990, p.11, 14 e 15. 
As preocupações de Robert Darnton, publicadas no ano de 1990, justamente em um contexto em que termos como "história em migalhas", "crise", "virada crítica", indicavam um momento sensível no ofício dos historiadores, momento este em que imperava a tensão entre "certezas e inquietações", outra expressão corriqueira do período. Indagava-se, além dos fundamentos epistemológicos da prática historiográfica, as condições de legitimidade cultural para os escritos históricos, sua razão de ser dentro da sociedade. A queda do muro de Berlim no ano anterior, aparentemente fez da história (para alguns o fim dela) uma questão candente para o pensamento, tornando atual ainda neste momento aquela infantil indagação levantada por uma criança algumas décadas antes: "papai, para que serve a história?". Ora, a pergunta hoje poderia muito bem ser intercambiada por outra, talvez ainda mais constrangedora: "papai, de que serve ler a história?".

Diante da complexidade dessa situação, que engendrou debates acalorados e enriquecedores, mas também discussões um tanto quanto despropositadas, este ensaio possui intenções mais modestas. É o tema da leitura da história que ocupará estas linhas. Pretendo sugerir, e apenas isso, que este tema não é apenas reflexo de alguns dos embates contemporâneos, mas sim uma reflexão que ocupou não poucos autores, historiadores ou não, ao longo do desenvolvimento da historiografia moderna, suas raízes sendo alimentadas mesmo por alguns autores antigos. Como sugestão, deixo duas hipóteses ainda prematuras mas que, assim espero, possam estabelecer as bases para um possível debate. Em primeiro lugar, tendo a considerar que o desenvolvimento do método histórico na modernidade, compreendida aqui desde o momento fundamental do humanismo renascentista italiano, segue concomitante à formulação de questões sobre a leitura da história, diria mesmo, em alguns casos, à formulação de teorias sobre a leitura da história. Em segundo lugar, como consequência desta primeira hipótese, acredito que as condições de legitimidade para a escrita historiográfica residem, não apenas nos procedimentos escriturários de que se valem os historiadores para fundamentar seus relatos, mas também no intervalo incerto e impreciso que articula a prática da escrita com o ato de leitura. O corolário de tudo isso seria a sugestão de que uma possível idéia de "verdade" na historiografia, apenas poderia ser vislumbrada de forma plena ao se considerar aquilo que Paul Ricoeur definiu como "pacto tácito de leitura", por meio do qual uma espécie de contrato entre historiador e leitor é firmado, sendo que ele apenas pode ser mantido no campo dialógico que une os dois personagens. ${ }^{2}$ As linhas que se seguem intentam substanciar tal discussão oferecendo ao leitor um pano de fundo historiográfico a partir do qual essas considerações podem ser aventadas.

2 RICOEUR, Paul. L'écriture de l'histoire et la représentation du passé. Annales HSS, Paris, n.4, juillet-août, p.731747,2000 
II.

No final de janeiro e início de fevereiro de 2005, Anthony Grafton proferiu na Universidade de Cambridge uma série de conferências dentro do plano das George Macaulay Trevelyan Lectures. Tendo por título What was history?, Grafton fez uma clara alusão às conferências dadas no mesmo contexto das Trevelyan Lectures por Edward Carr, cerca de quadro décadas antes. ${ }^{3}$ Carr escrevera numa ocasião em que ele próprio reconhecia o ambiente de ceticismo quanto às possibilidades do conhecimento histórico. Valendo-se do exemplo de dois momentos bastante específicos da historiografia anglosaxã, duas "encarnações" escreveu ele, da Cambridge Modern History, demonstrou as transformações por que passava a disciplina da história entre o otimismo então considerado descabido de Lord Acton, na carta-plano endereçada aos colaboradores da coletânea em fins do século XIX, e o pessimismo que, por uma série de razões que não convém aqui enumerar, encontrou terreno fértil na metade do século XX e habitou as palavras de Sir George Clarck na introdução geral à segunda edição da obra. ${ }^{4}$

Edward Carr procurou desenvolver a pergunta por ele mesmo colocada, "o que é a história?"; indagação que hoje se multiplicou em inúmeros outros questionamentos: como se escreve a história?, como se opera o conhecimento historiográfico?, como funciona, no interior de um grupo social, o saber dito histórico?, qual o estatuto do historiador nas sociedades em que atua? etc., os quais fizeram avançar e tornaram mais complexa (e instigante) a tarefa de estudar a historiografia. Entre as muitas considerações tecidas pelo historiador inglês, uma é de particular interesse para as intenções aqui esboçadas. Já no início do livro, findando o primeiro capítulo, ele oferece uma primeira abordagem para sua pergunta: a história seria a constante interação entre o historiador e os fatos, um diálogo entre o presente e o passado. Por detrás da obviedade, essa interação pressupõe uma perspectiva importante. Recusando o mecanicismo que considera o ofício do historiador como, primeiro, a leitura em massa dos documentos e, segundo, a escrita de um texto que os interpreta e os explica, o autor sugere uma postura mais flexível em que a leitura e a escrita da história, a primeira feita sobre os documentos e a segunda a partir deles, seguem de forma simultânea, uma possibilitando o desenvolvimento da outra. Assim, ele coloca num mesmo plano analítico dois pontos fundamentais para a compreensão dos preceitos que embasam o conhecimento histórico, ainda que não os desenvolva de forma plena: a história se escreve e, antes, durante e depois disso, a história é lida, sendo o historiador, simultaneamente,

3 GRAFTON, Anthony. What was history? The art of history in early modern Europe. Cambridge: Cambridge University Press, 2007

4 CARR, Edward Hallett. What is history? The George Macaulay Trevelyan Lectures delivered in the University of Cambridge, January - March 1961. London: MacMillan \& Co. Ltd., 1962. 
tanto escritor como leitor de histórias. Produto de um trabalho complexo de escrita, ela é igualmente o resultado de uma tarefa não menos complexa de leitura. Assim, à pequena lista de indagações levantadas no início deste parágrafo, pode ser acrescentada a questão como se deve ler a história? E é sobre este último ponto que seu colega de lectures se deterá longamente, passadas quatro décadas desde sua intervenção em Cambridge.

Anthony Grafton é atualmente um dos mais importantes e prolíficos historiadores que se debruçam sobre a história da sua disciplina, notadamente sobre o período que pode ser considerado fundador da moderna historiografia, entre o humanismo renascentista e princípios do lluminismo; aquilo que é por ele mesmo definido como history of scholarship. Como ex-aluno de Arnaldo Momigliano, Grafton reconhece explicitamente no livro a dívida intelectual que mantém com seu antigo professor, embora saliente que, entre a gama de estudos enciclopédicos com os quais se deparou, o historiador italiano não conferiu à temática da leitura da história senão considerações tangenciais. Pois é justamente o estudo erudito e aprofundado do tema que Grafton se propõe nas quatro conferências proferidas, abordando a emergência, os desenvolvimentos e a "morte" de um gênero, a ars historica, que marcou sobretudo o pensamento histórico humanista nos entornos de 1600, tendo por intenção primordial oferecer os fundamentos, não apenas de como se deveria escrever a história, mas sobretuto de como ela deveria ser lida.

Se Grafton não menciona o fato, não custa lembrar que o autor mesmo em cuja homenagem tanto ele como Carr elaboraram suas reflexões já havia, ainda que de forma bastante passageira e sob outro prisma, abordado o tema. No dia 30 de maio de 1945, George Macaulay Trevelyan pronunciou um discurso no âmbito da terceira conferência anual da National Book League, na Inglaterra, tendo por título justamente History and the reader. Segundo as palavras do apresentador da tradução francesa do texto, "em uma época onde os leitores de obras históricas são numerosos, é particularmente útil que se interrogue sobre a mensagem que pode trazer a história". ${ }^{5}$ Talvez de forma não propositada, fez-se eco à toda a tradição que remonta aos autores estudados por Grafton, segundo a qual saber ler a história significava, entre outras coisas, ser capaz de apreender seus ensinamentos políticos e, acima de tudo, morais. Trevelyan ele próprio coloca nesse sentido suas palavras, indagando sobre o valor moral da história para a formação de um "espírito público". Para o historiador inglês,

o erudito paciente que se lança à pesquisa histórica científica, e o leitor que percorre de maneira mais negligente (plus nonchalamment) as páginas da história,

5 VERLINDEN, Charles. Présentation. In: TREVELYAN, George Macaulay. L'histoire et le lecteur. Bruxelles : Office de Publicité, 1946, p.7. 
são ambos capturados pelo mistério do tempo, pela mutabilidade de todas as coisas, pela sucessão de épocas e de gerações. ${ }^{6}$

Menos otimista que seu apresentador, Trevelyan ressalta umas das conseqüências funestas dessa "mutabilidade de todas as coisas", a qual se fez notadamente perceptível durante os anos que antecederam as palavras enunciadas. Falando diante de uma associação de livreiros, ele ressaltou a crise no mundo da leitura neste momento logo após os conflitos que varreram boa parte da Europa e que ainda produziriam efeitos devastadores em outras partes do planeta. Vivia-se num contexto de penúria de papel que implicava em altos custos para a publicação de novas obras. Além disso, ainda segundo o autor, a situação bélica teria também colocado em risco uma geração de historiadores incumbidos antes de fazer a guerra que de escrever a história. ${ }^{7}$ Por fim, num arroubo aristocrático, considerou prejudicial, pelo menos neste ponto em específico, a nova formação social que se estabeleceria no pós-guerra marcada pelo princípio de igualdade social e que, num inusitado raciocínio, fez o autor sugerir que novas e menores habitações seriam construídas acarretando o fim das grandes bibliotecas particulares, sendo que as públicas não conseguiriam suprir a demanda pela leitura. Em poucas palavras, o que a posição do Regius Professor da Universidade de Cambridge faz perceber é a ligação estreita entre as possibilidades, materiais e intelectuais, de se ler história e as condições de validade do saber histórico; colocados obstáculos as primeiras, coloca-se também em risco as segundas.

Enfim, entre os eruditos humanistas estudados por Grafton nas suas conferências e o texto do próprio Trevelyan sobre a leitura da história, não foram poucos os autores, embora nem sempre com efeitos mais evidentes, que dedicaram palavras, alguns de maneira mais produtiva, outros de forma mais sintética, ao tema de como se deveria ler a história. A atenção conferida a algumas de tais palavras pode lançar luz em um ponto que me parece de grande importância para os atuais estudos de história da historiografia, a saber, as formas e condições de legitimidade do discurso produzido pelos historiadores. Desde logo cabe ressaltar que esta atenção aqui sugerida será mantida de forma retrospectiva, partindo do presente para o passado. Iniciada com estas breves considerações de historiadores do século XX, culminará com outras breves considerações sobre o contexto estudado por Anthony Grafton no século XVI.

6 TREVELYAN, George Macaulay. L'histoire et le lecteur, p.20.

7 Trevelyan fala sobre o recrutamento de estudantes das humanidades que não teriam tempo nem condições de se dedicar e exercer o ofício de sua formação. 


\section{III.}

Neste retrospecto sumário, eclético e reconhecidamente incompleto, um ponto de parada interessante é o ano de 1836. Nele, um curioso empreendimento editorial tem seu ano de início: trata-se da coleção La Science Populaire de Claudius. Simples discours sur toutes choses, publicada em 34 volumes in-24, entre 1836 e 1841, impressos com preciosos cuidados e repletos de gravuras, variando de 60 a 100 páginas cada, vendidos, segundo o prospecto, a preços módicos. Ou seja, uma espécie de enciclopédia visando a um público leitor amplo, como o próprio nome dá a entender. Seu autor foi Charles-Claude Ruelle, que assumiu para si o pseudônimo que deu nome à coleção. No quarto volume, então, é publicado o texto De la manière d'écrire et de lire l'histoire. Claudius se detém sobretudo nas histórias impressas sobre a França, cuja primeira obra seria, para ele, seguindo informações dadas por Augustin Thierry cerca de quinze anos antes, as Grandes Chroniques, publicadas em 1476. Acompanhando o movimento que segue desde os primeiros textos impressos até a década de 1830, o artigo tematiza os contornos do interesse social que caracterizaram a cultura histórica oitocentista. Em primeiro lugar, é colocado o problema da autenticidade dos trabalhos historiográficos, já que, pensando em termos dos usos possíveis da história, o registro do falso seria desprovido de utilidade. Quanto a isso, a solução fundamental para os historiadores estaria no recurso direto à documentação, confrontando-a com os relatos elaborados por outros historiadores. A necessidade disso viria do fato de que, para o autor, "nossos historiadores não falam do passado senão por ouvir dizer, como de uma região distante, que eles não teriam necessidade de ver, outros tendo-a visitado no lugar deles". ${ }^{8}$ Dessa maneira, "é o retorno às fontes que faz cair todos esses adornos enganosos que nós tomamos como a imagem verdadeira dos tempos antigos; este mesmo retorno às fontes nos fornecerá os materiais da história". ${ }^{9}$

Claudius segue definindo os procedimentos metódicos para os historiadores, os quais devem realizar uma "triagem dos fatos, a apreciação dos testemunhos, a discussão das provas, a avaliação das causas de erro; obra imensa de sagacidade, de discernimento, ou como se diz em grego, de crítica". ${ }^{10}$ Aliado a isso, passados os princípios da boa crítica, o autor reconhece o papel importante da imaginação na construção do discurso historiográfico. Para ele, não se trata de escrever histórias poéticas, mas histórias "onde a forma do passado revive inteira, visível e sensível: onde a realidade seja reproduzida sob cores realmente comoventes, que, sendo

8 [RUELLE, Charles-Claude]. De la manière d'écrire et de lire l'histoire. In: La Science Populaire De Claudius. Simples discours sur toutes choses. Paris: Librarie de Jules Renouard, 1836, vol.4, p.13.

9 [RUELLE, Charles-Claude]. De la manière d'écrire et de lire l'histoire, p.14.

10 [RUELLE, Charles-Claude]. De la manière d'écrire et de lire l'histoire, p.15. 
fechado o livro, as lembranças que ele nos deixa se assemelhem àquilo que se relata após uma excursão em terra estrangeira". ${ }^{11}$ Disso decorre a questão que nos interessa mais de perto: o papel da leitura da história em todo este processo. Afinal, indaga o autor, "por que nós [leitores] não ajudaríamos no efeito que o historiador deve produzir?", efeito este que, segundo os princípios acima mencionados, deveriam apontar para a autenticidade do relato histórico. ${ }^{12}$

Assim, Claudius defende que, do mesmo modo como o historiador deve conhecer plenamente a cena narrada, o leitor deve ele também assumir para si uma experiência particular de conhecimento: deve viajar, seguir relatos de viagem, visitar museus, ler romances, imaginar a história que lê e completá-la. O leitor criaria, com isso, a capacidade de verificação do relato que the é fornecido. Tal como para quem se põe a escrever histórias, o trabalho de leitura é todo ele perpassado pelos princípios da crítica e pela dimensão da imaginação. No juízo do autor, um nome parece ter encarnado plenamente esta dupla perspectiva: "quantas coisas este nome deverá resumir de uma só vez! um trabalho invencível, uma erudição que vivifica a imaginação no lugar de matá-la; ao mesmo tempo os procedimentos do poeta e do químico". Uma história da França toda ela feita de fontes originais; "uma sensibilidade que nos tempera a secura da ciência, e adocica um pouco os embargos da inexorável Natureza". Alguém que lembre que aqueles sobre quem se fala são homens como aqueles que deles falam; um homem, enfim, que se transforme em espírito e em verdade, que para falar do povo se faz povo e que para escrever a história, soube ler com exatidão suas singularidades: um nome, e este nome é Jules Michelet. ${ }^{13}$

Algumas décadas antes de Fustel de Coulanges ter comparado o trabalho do historiador com o do químico, encarando o primeiro acima de tudo como um leitor de textos, Claudius atribui para este personagem quase que antagônico a Fustel um lugar de excelência na cultura histórica francesa. ${ }^{14}$ Mas o que importa reter disso tudo é o fato significativo que, em uma obra cujas intenções são claramente de vulgarizar os campos de saber (o texto seguinte, por exemplo, é um discurso sobre eletricidade), popularizando os critérios utilizados na produção dos diversos tipos de conhecimentos, ao leitor da história é atribuída uma atividade extremamente complexa: ele não é apenas o indivíduo que busca fruição nos registros históricos, que assume passivamente aquilo que lhe é oferecido nos relatos sobre o passado, como a imagem criada por Darnton pode dar a impressão. Pelo contrário, a ele é reservado o papel de ajuizar sobre a autenticidade do texto

11 [RUELLE, Charles-Claude]. De la manière d'écrire et de lire l'histoire, p.28.

12 [RUELLE, Charles-Claude]. De la manière d'écrire et de lire l'histoire, p.28.

13 [RUELLE, Charles-Claude]. De la manière d'écrire et de lire l'histoire, p.69.

14 Ver sobre isso HARTOG, O século XIX e a história. O caso Fustel de Coulanges. Rio de Janeiro: Ed.UFRJ: 2003, p.18-19. 
lido, verificar seus princípios de legitimidade e atestar, por fim, a validade do que é relatado. Para isso, compete-lhe tanto compreender os pormenores da crítica histórica, tornando-se apto a refazer o caminho percorrido pelos escritores da história, quanto realizar um trabalho imaginativo, dotando o texto da concretude necessária para tornar o passado novamente "experienciável". Neste caso, o leitor é juiz em uma dimensão ainda mais ampla que aquela que Ihe foi conferida por Wilhelm von Humboldt ao final do século XVIII, quando afirmou que "o historiador, uma vez que ele mostrou os eventos de uma época tal como eles naturalmente se desenvolveram, pode se contentar de deixar ao leitor o cuidado de julgar". ${ }^{15}$ Neste caso, a imparcialidade requerida para a escrita da história cedia espaço para a valoração moral dos fatos no âmbito da leitura. No caso de Claudius, por sua vez, o julgamento da parte do leitor deveria incidir igualmente sobre o texto onde os fatos foram registrados, a leitura constituindo-se ao mesmo tempo como um olhar imparcial, metodicamente conduzido, tanto sobre a história enquanto devir, como sobre a história na forma narrativa. Escrita e leitura parecem habitar o mesmo espaço delineado pelas regras da prática historiográfica, justamente no contexto em que o saber histórico se institucionaliza e assegura a si mesmo um grau considerável de autonomia diante de outros espaços discursivos.

Além de Michelet, há outra presença importante nas considerações de Claudius: Augustin Thierry, cujas cartas sobre a história da França começaram a vir a público a partir do ano de 1820. Thierry ele próprio advertiu seus interlocutores que as motivações que o levaram a escrever as cartas se deram justamente a partir de uma experiência particular de leitura: a desconfiança em relação aos historiadores contemporâneos. Procurando nos livros de história o apoio plausível para suas convicções políticas, encontrou nela uma forma de prazer incitada pela leitura. Sem se dar conta, como escreveu ele, passou dos livros modernos para os velhos escritores, das histórias para as crônicas e pôde, nas suas palavras, "ver a verdade sufocada sob as fórmulas de convenção e o estilo pomposo" dos historiadores que lhe eram coetâneos..$^{16}$ Interessado, sobretudo, na história medieval, no momento em que a história da França sucederia à história dos reis francos, Thierry se colocava a tarefa de corrigir os abundantes equívocos que marcavam boa parte das obras existentes e que transformavam o erro em senso comum. "Instruído por aquilo que me custou um esforço para refazer, sozinho e sem guia, minha educação histórica, eu me proponho a facilitar este trabalho àqueles que desejarão empreendê-lo e

15 HUMBOLDT, Wilhelm von. Le dix-huitième siècle. Plan d'une anthropologie comparée. Introduction de Jean Quillien. Lille: Presses Universitaires de Lille, 1995, p.78-79.

16 THIERRY, Augustin. Lettres sur l'histoire de France pour servir à l'étude de cette histoire. Septième édition. Paris: Just Tessier, 1842, p.2. 
substituir por um pouco de verdade as ninharias do colégio e os preconceitos do mundo". ${ }^{17}$ Ou seja, ele assume o lugar específico e privilegiado de um leitor crítico da história e dos historiadores, o que se evidencia na carta V, cujo título é Sur les différentes manières décrire l'histoire, en usage depuis le XVI siècle. ${ }^{18}$ Neste texto torna-se clara a função especializada do leitor, que deve ser um conhecedor dos princípios norteadores da prática historiográfica, como o próprio Thierry se colocava. Nesse sentido, se sua intenção era oferecer um conjunto de regras renovadas para se escrever a história e, com isso, evitar os equívocos de alguns dos historiadores que o precederam, o estabelecimento deste método novo seguia pari passu com a prática da leitura crítica dos textos anteriores; é ela o princípio norteador da reflexão de Thierry.

Não seria essa, afinal, a posição colocada na referida carta, quando Thierry defendeu o justo equilíbrio entre a historiografia literária e a historiografia filosófica, considerando que o comentário de moral não poderia seguir desprovido do esforço de narração, nem este deveria prescindir daquele? Além disso, em termos de prática erudita haveria muito ainda por se fazer no intuito de evitar as falsidades da história. Contudo, para aquele momento não bastaria mais apenas o rigor factual, pois, como escreveu ele,

há, no fato de história, mais de um gênero de exatitude; e se o trabalho dos cronologistas nos protegeu desde então das falsidades materiais, é necessário um novo trabalho, uma nova arte, para afastar igualmente a falsidade de cor e de caráter. Não pensemos que basta dirigir julgamentos morais sobre os personagens e os eventos: trata-se de saber se os homens e as coisas existiram realmente tal como eles nos são representados; se a fisionomia que se thes empresta Ihes pertence verdadeiramente, e não é de modo algum mal transportada do presente ao passado (...). É aí que reside a dificuldades e o trabalho; aí estão os abismos da história, abismos imperceptíveis de escritores superficiais, e preenchidos algumas vezes, sem proveito, pelos trabalhos de uma erudição que eles desdenham. ${ }^{19}$

A erudição que Thierry defende, portanto, é a erudição da leitura sobre os textos de história, do trabalho erudito que o leitor deve dirigir aos escritos dos historiadores ou daqueles que se ocuparam de escrever sobre o passado. A atenção demandada não deve se limitar aos aspectos factuais, mas também dirigir-se aos desenhos gerais da narrativa histórica, avaliando a propriedade com que os objetos são "pintados"; o leitor é ele próprio um apreciador de quadros, um andarilho das galerias, um visitador dos museus, como diria mais tarde Claudius.

17 THIERRY, Augustin. Lettres sur l'histoire de France, p.4.

18 Sigo o texto da sétima edição citada na nota 17.

19 THIERRY, Augustin. Lettres sur l'histoire de France, p.84. 


\section{IV.}

As considerações sobre a leitura da história pareciam ocupar um lugar importante nas reflexões tecidas sobre a prática dos historiadores, pelo menos no mencionado contexto francês da primeira metade do século XIX. Se Claudius nos mostra como elas poderiam interessar a um público mais amplo, Thierry indica que dentro do próprio métier elas deveriam ser levadas em conta. Há um outro exemplo que, embora curto, parece-me significativo. Estamos já, no sentido deste retrospecto, no final do século XVIII, acompanhados por um personagem tão obscuro quanto ressentido, M. Desmarest. O ano é 1790, quando se publica o texto do referido personagem, Mes apperçus sur la religion, sur l'égalité parmi les hommes, sur l'esprit, sur la maniere de lire l'histoire, sur les livres de controverse, sur les duels, sur la guerre, sur la musique, sur la danse. Ao que tudo indica, parece que um arroubo literário tomou conta de Desmarest, o qual resolveu, então, diante de um mundo que desabava à sua frente, escrever sobre tudo que the parecia digno de nota, colocando lado a lado, em termos de importância, a reflexão sobre o espírito e a igualdade entre os homens, as considerações sobre a música e a dança, assim como a maneira própria para se ler a história. Suas idéias são claras e evidentes: ler bem a história significa saber reconhecer nela aquilo que pode ter valia para a atuação no presente, um modelo passível de ser imitado, afinal, para ele a história fornecia ensinamentos. "Não é de modo algum a cronologia nem os relatos de batalhas que se deve procurar na história, mas o quadro geral dos diversos governos, das leis, das paixões, e esta moral que nasce dos fatos e que não é percebida por todas as pessoas". ${ }^{20}$ Enquanto fonte de lições morais, a história é colocada no mesmo plano da fábula, pois, para o autor, um texto de La Fontaine, desde que bem meditado, isto é, bem lido, vale por um tratado de moral: "quanta moral, quanta instrução não se encontra no discurso de uma raposa, de um lobo, enfim, de todos os animais introduzidos na cena?". ${ }^{21}$ Neste caso preciso, o aspecto crítico da leitura deixa espaço para uma perspectiva menos metódica e mais moralista; a utilidade esperada da leitura da história viria menos da sua dimensão realista do que da capacidade estilítica daquele que escreve.

Nas considerações por ele escritas sobre a igualdade entre os homens, talvez seja possível vislumbrar uma das lições mais preciosas por ele mesmo tirada da história: a constatação de que tal igualdade é impossível, posto que não é natural. Os indivíduos, assim como todos os seres, são naturalmente diferentes. No plano social, uns são feitos para governar, outros para

20 DESMAREST, Ancien Fermier-Général du Roi. Mes apperçus sur la religion, sur l'égalité parmi les hommes, sur l'esprit, sur la maniere de lire l'histoire, sur les livres de controverse, sur les duels, sur la guerre, sur la musique, sur la danse, 1790, p.13

21 DESMAREST, Ancien Fermier-Général du Roi. Mes apperçus, p.14. 
serem governados; reside aí o fundamento da sociedade, como a história, pelo menos até então, parecia mostrar. Isto fica explícito em uma máxima peculiar transcrita no texto: "é infinitamente perigoso deixar introduzir a confusão dos estados, e apagar a linha de demarcação que os separa (...) cada classe deve ter suas funções a serem cumpridas, e a opinião contrária não apresenta senão ilusões pérfidas". ${ }^{22}$ Uma posição compreensível, vinda de um indivíduo que até bem pouco tempo atuava como funcionário régio na coleta de impostos e que, lendo a história que acontecia diante de seus olhos, desde o ano anterior ao seu escrito, parecia se ressentir da desordem social que desarranjava a história com a qual estava acostumado. Quem sabe para Desmarest, a boa leitura da história seria também uma forma de reorganizar a confusão, colocando em ordem tudo aquilo que estava "fora do lugar".

Um outro exemplo, ainda no século XVIII e ainda no contexto francês, mas bem anterior à Revolução. Trata-se da obra do abade Nicolas Lenglet du Fresnoy, cujo longo título é mais do que significativo para o tema que aqui se trata: Méthode pour étudier l'histoire où après avoir établi les principes \& l'ordre qu'on doit tenir pour la lire utilement, on fait les remarques necessaires pour ne se pas laisser tromper dans la lecture: avec un Catalogue des principaux Historiens, \& des remarques critiques sur la bonté de leurs Ouvrages, \& sur le choix des meilleures Editions, publicada em dois tomos em 1713. Segundo Blandine Kriegel, a obra foi duramente criticada por Charles-François Toustain e René Prosper Tassin, religiosos beneditinos da congregação de Saint Maur, que se dedicaram a reescrever, para o século XVIII, o tratado de diplomática de Jean Mabillon. ${ }^{23}$ Fato curioso ou não, foi o próprio Du Fresnoy quem elaborou o verbete Diplôme \& Diplomatique, publicado no tomo IV da Encyclopédie de Diderot e D'Alembert. Para a autora, o verbete é um dos indícios eloquentes da "derrota da erudição", vislumbrada por ela em meados do século da Luzes, sobretudo a partir do projeto editorial encabeçado pelos dois filósofos. Segundo Kriegel, Du Fresnoy marca uma inversão completa do princípio da erudição tal como ela despontara no século anterior, uma vez que o abade concedia uma legitimidade maior para as histórias escritas a partir de autores contemporâneos aos fatos do que àquelas escritas a partir de títulos ou diplomas; ou seja, para ele, as fontes de segunda mão se sobrepõem às chamadas fontes primárias.

Talvez tenha sido esta mesma perspectiva que inspirou Du Fresnoy a escrever, algumas décadas antes, seu trabalho sobre a leitura da história. Afinal, como ele salienta desde o início do prefácio, "estuda-se a história,

22 DESMAREST, Ancien Fermier-Général du Roi. Mes apperçus, p.12.

23 KRIEGEL, Blandine. L'histoire à l'Age classique II: la défaite de l'érudition. Paris: Quadrige/PUF, 1996, p.307 e ss. 
sem saber nem como, nem em que Autores se deve estudá-la". ${ }^{24}$ A história estava nos livros, não nos arquivos; mesmo porquê, eles ainda não haviam adquirido o status epistemológico privilegiado que o século seguinte lhes concederia. O que ele procura evitar com seu manual, é que se continue a fazer "uma leitura desconsiderada de todos os tipos de Historiadores", afinal "não basta ler, é preciso ler de forma produtiva", e para tanto há a necessidade de método. Nesse sentido, seu livro não é destinado àqueles que procuram na história um simples passatempo, mas sim aos leitores que intentam ler os trabalhos dos historiadores da forma crítica mais adequada aos desígnios da atividade historiográfica.

Para Du Fresnoy, o bom leitor de história é aquele capaz de avaliar plenamente o escrito que é dado à leitura, desde seus mecanismos formais de elegância e estilo, até a propriedade na representação dos fatos narrados. ${ }^{25}$ A boa leitura prevê o bom uso da história, escolhendo entre o bem e o mal para, evitando-se este, imitar aquele,

pois saber, significa conhecer as coisas pelos seus princípios: assim, saber a história, é conhecer os homens que fornecem sua matéria; é julgar judiciosamente estes homens: estudar a história é estudar os motivos, as opiniões e as paixões dos homens, para penetrar em todas as suas atividades, seus caminhos e descaminhos (les tours \& les détours): enfim, para conhecer todas as ilusões feitas ao espírito e as surpresas feitas ao coração; em uma palavra, é aprender a se conhecer a si mesmo nos outros (se connoître soy-même dans les autres). ${ }^{26}$

Para tanto, o autor traça um amplo e complexo itinerário que deve ser percorrido pelo leitor. Em primeiro lugar, elenca uma série de saberes que devem preceder o estudo da história, entre os quais a geografia e a cronologia, considerados desde há muito os olhos da história, bem como o estudo dos costumes, religiões e tradições dos povos. Em seguida, há uma ordem precisa a ser mantida: começa-se pelas leituras dos resumos de história universal e só então é possível se dedicar às histórias particulares, as quais certamente terão seu sentido mais inteiramente estabelecido. O plano geral dá ao leitor a capacidade de melhor avaliar as conjunturas individuais, situando-as de acordo com suas singularidades. A ordenação

24 LENGLET DU FRESNOY, Nicolas. Méthode pour étudier l'histoire où après avoir établi les principes \& l'ordre qu'on doit tenir pour la lire utilement, on fait les remarques necessaires pour ne se pas laisser tromper dans la lecture: avec un Catalogue des principaux Historiens, \& des remarques critiques sur la bonté de leurs Ouvrages, \& sur le choix des meilleures Editions. Paris: Chez Antoine Urbain Coustelier, M. DCCXIII, [1713] , tome I, prefácio não paginado.

25 "Et ceux qui se picquent de litterature \& d'érudition, se persuadent qu'ils ont beaoucoup fait, quand ils ont remarqué dans les Historiens tout ce qui concerne la proprieté des termes; l'élégance \& la politesse du discours; les coûtumes \& les usages anciens; la description des lieux particuliers; la suite \& la viciscitude des Empires; les commencemens de toutes les Religions, \& les chagemens memorables, qui y sont arrivez; l'établissement des Villes; l'origine, les richesses, \& la puissance des Peuples, les prodiges; enfin tout ce qu'il peut y avoir de remarquable dans l'antiquité". LENGLET DU FRESNOY, Nicolas. Méthode pour étudier l'histoire, p.2.

26 LENGLET DU FRESNOY, Nicolas. Méthode pour étudier l'histoire, p.4. 
dos impérios históricos no tempo ganha assim um sentido pleno: Caldeus, Egípcios, Assírios, Persas, Medos e outros impérios; os gregos assumiriam um lugar à parte e a história romana, bem como da igreja cristã, um destaque especial.

Após discorrer sobre o conjunto destes temas, Du Fresnoy enumera os "socorros" (secours) que devem auxiliar no trabalho dos historiadores. As memórias e cartas são por ele definidas como as fontes mais fidedignas, embora não deixe de fazer menção a diplomas, inscrições, medalhas como matérias propícias para o entendimento do passado, desde que passadas pelo crivo da autenticação. Na sequência de sua reflexão, os princípios que deveriam nortear a leitura das obras históricas. Desde logo é apontada a regra principal: "na leitura da história, não se deve ser, em verdade, nem excessivamente crédulo nem afetar-se de um Pirronismo, fazendo-se conveniente de duvidar de tudo". ${ }^{27}$ Se a credulidade cega conduz ao erro, o ceticismo exacerbado impede que da história se tirem lições. Du Fresnoy indica, nesse sentido, a justa medida em que se deve estabelecer a crença nos historiadores lidos; crença que deve ser fundada a partir dos próprios princípios metódicos que determinaram a escrita da história. Alguns outros procedimentos podem ainda orientar os leitores: escolher de preferência poucos, mas exatos, historiadores para seguir, evitando com isso se perder na quantidade de registros possíveis; levar em consideração se os autores escrevem sobre sua própria nação ou sobre terras estrangeiras; ler em conjunto, além dos historiadores, aqueles que os criticaram anteriormente.

Nicolas Lenglet du Fresnoy é um exemplo notório, no princípio do século XVIII, dessa demanda metódica sobre o estudo da história e sua correlata indagação sobre as maneiras de se ler a história. Com o caráter de manual, sua obra conta ainda, no segundo tomo, com uma variada lista de autores que trataram da maneira de se escrever e de se ler a história. No caso específico das obras voltadas a definir as regras de leitura, contam-se trinta e três livros mencionados, desde o tratado de Luciano de Samósata até textos publicados nos primeiros anos do século XVIII, sendo que trinta deles são de autores diferentes, o que me parece representativo da importância assumida por esta reflexão, pelo menos até os primeiros clarões das Luzes, quando a erudição começa a ser deslocada do lugar a que the foi atribuída desde o humanismo italiano, o que possivelmente fez escassear, ainda que não desaparecer por completo, os discursos sobre a leitura da história.

27 LENGLET DU FRESNOY, Nicolas. Méthode pour étudier l'histoire, p.363. 


\section{V.}

Se a atenção até aqui privilegiou o contexto francês, é possível ainda, mesmo que sem atravessar definitivamente o Canal da Mancha, notar como o mesmo problema também ocupou autores que escreviam em língua inglesa. Por volta da mesma época em que Du Fresnoy esboçava suas inquietações sobre a prática historiográfica, seja no manual de 1713, seja no artigo da Encyclopédie, Henry St. John, primeiro Visconde de Bolingbroke, elaborou algumas de suas famosas cartas sobre o estudo e o uso da história, escritas quando de seu retiro em terras francesas a partir de meados da década de 1730. Desde a primeira carta, Bolingbroke ressalta o que entende como formas distintas de leitura da história. ${ }^{28} \mathrm{Em}$ primeiro lugar, há aqueles leitores que não procuram no estudo histórico senão divertimento, lendo a vida de Alexandre ou de César como quem participa de um jogo de cartas. Há outros cujos motivos em nada são melhores aos primeiros, pois almejam apenas o brilho das conversas mundanas e que, desprovidos de idéias próprias, encontram nos autores antigos as máximas que não conseguiram pensar, tornando-se, inclusive, um estorvo pedante dentro da sociedade. Bolingbroke considera que a primeira forma de leitura seria peculiar aos ingleses, enquanto que a segundo caracterizaria notadamente os leitores da França.

Entretanto, há formas de leitura superiores com as quais é possível se ocupar de modo mais proveitoso, realizadas por aqueles cujos estudos não os tornam mais sábios ou melhores, mas que procuram facilitar a vida de outros leitores. São copistas de difíceis manuscritos, restabelecendo textos obscuros e corrigindo-os segundo os preceitos das normas gramaticais mas que, infelizmente, não conseguiram ultrapassar este nível fundamental de leitura, nem alçaram grandes voos eruditos sobre os textos. Há ainda uma quarta categoria de estudiosos ou leitores de história, "homens do primeiro escalão do conhecimento e para os quais toda a tribo dos eruditos se curva em reverência". ${ }^{29}$ Incansáveis pesquisadores da antiguidade, dos sistemas de cronologia e da história, que encontraram em Joseph Justus Scaliger um dos seus nomes mais proeminentes. Estudiosos que trabalhavam com materiais escassos, "eles os combinaram em todas as formas que lhes podem ser dadas; avaliaram, conjecturaram, rearticularam passagens desarticuladas de diferentes autores, e romperam com tradições de originais incertos" ${ }^{30}$ Mas Bolingbroke, refletindo o brilho nascente das Luzes filosóficas, se mostra também receoso diante dessa

28 Duas foram as edições consultadas, com diferenças sensíveis de texto mas que não alteram a idéia geral do autor: BOLINGBROKE [Henry Saint-Jean]. Lettres sur l'histoire. Tome Premier. Sur l'étude et l'usage de l'Histoire, 1752; BOLINGBROKE [Henry St John]. Letters on the study and use of history. A new edition corrected. Paris: Teophilus Barrois, 1808.

29 BOLINGBROKE [Henry St John]. Letters on the study and use of history, p.4.

30 BOLINGBROKE [Henry St John]. Letters on the study and use of history, p.5. 
prática erudita, sugerindo que em muitos casos (citando Eusébio da Cesaréia) os sistemas de história elaborados acabam por corromper as fontes originais, tentando fazer convergir às cronologias profanas de forma que elas se adequassem ao tempo próprio da história sacra. Nesse sentido, ele procura se colocar em um lugar mais elevado da crítica, como leitor consciencioso destes mesmos leitores da história por ele mencionados, estabelecendo os critérios para a prática da leitura atenta: "precisamos examinar escrupulosa e indiferentemente os fundamentos sobre os quais eles [os eruditos mencionados] se amparam; e se os considerarmos pouco prováveis ou grosseiramente improváveis, seria tolice vislumbrar sobre eles um edifício algo melhor". ${ }^{31}$

Ou seja, é sobre os princípios da crítica erudita realizada pelos autores de história que o olhar do leitor deve incidir, antes mesmo de avaliar o resultado final da escrita realizada. Mas o leitor advertido, para Bolingbroke, que manteve relações com uma série de historiadores filósofos da França, alguns dos quais encabeçaram a reação da filosofia sobre a erudição, deve se manter a uma distância segura das miudezas eruditas: nas suas claras palavras, é preferível cometer alguns pequenos equívocos factuais ou mesmo erros de ordem cronológica, do que "sacrificar metade da vida coletando os cacarecos eruditos (learned lumber) que entulham a cabeça de um antiquário". ${ }^{2}$ O leitor crítico, neste caso, é também um leitor-filósofo. Seria apenas sob estes princípios que o estudo da história visando sua utilidade poderia ser realizado adequadamente.

As considerações tanto de Bolingbroke quanto de Du Fresnoy parecem marcar o momento em que ocorre um deslocamento considerável no entendimento que se fazia do modo pelo qual a história poderia ser estudada e, por conseguinte, da maneira pela qual as histórias poderiam ser lidas. Situar a discussão no contexto do processo sinalizado por Blandine Kriegel da chamada "derrota da erudição" é um encaminhamento plausível mas que requer uma atenção especial: trata-se, de fato, apenas disso? Uma pergunta simples mas cujas complexas consequências devem ser devidamente pesadas. Afinal, aquilo que se demandava aos leitores de história, isto é, a atenção crítica aos fundamentos metódicos da prática historiográfica parece se manter até o século XIX, ainda que sob matizes distintos: Du Fresnoy parece privilegiar as fontes de segunda-mão, se assim se pode falar, em detrimento do estudo mais apurado dos diplomas, mas faz questão de reconhecer em tal estudo sua importância fundamental para a escrita da história; Bolingbroke, por sua vez, parece desejar ultrapassar o simples registro dos produtores de anais, bem como as miudezas da prática antiquária, mas procura a todo momento encontrar as garantias para uma história

31 BOLINGBROKE [Henry St John]. Letters on the study and use of history, p.6.

32 BOLINGBROKE [Henry St John]. Letters on the study and use of history, p.7. 
autêntica e chega inclusive a se valer da ideia de uma "história completa", tópica recorrente a diversos autores humanistas, como a noção de histoire accomplie, de La Popelinière, ou a historia integra, de François Baudouin. ${ }^{33}$ Tais questões precisariam, evidentemente, de um desenvolvimento que não seria possível de realizar aqui. Mas creio que elas reforçam a hipótese levantada logo no início, segundo a qual as discussões realizadas sobre o método e sobre a escrita da história seguem acompanhadas pelas formulações "teóricas" sobre as maneiras pelas quais as histórias deveriam ser lidas; as alterações nas primeiras, parecem implicar mudanças significativas também nas segundas.

\section{VI.}

Se o século XVIII pode ser de fato caracterizado como um momento em que o pensamento historiográfico moderno deslocou as questões relativas à leitura e ao estudo da história, os dois séculos precedentes são, por sua vez, o contexto de apogeu desta inquietação, momento em que os tratados de ars historica atingiram um considerável grau de divulgação.

Uma obra publicada em 1614 merece destaque neste retrospecto. Trata-se do livro La manière de lire l'hstoire, escrito pelo embaixador do duque de Savóia junto ao rei Henrique III da França, René de Lucinge. ${ }^{34}$ Doutor em direito pela prestigiosa Universidade de Toulouse, em 1576, publicou alguns trabalhos pertinentes a sua área de atuação, isto é, a diplomacia, dentre os quais destaca-se a obra De la naissance, durée et chute des états, vinda ao público em 1588. Cerca de quinze anos antes, participou da cruzada empreendida pelo Duque du Maine contra os turcos. Ou seja, tal como uma geração de letrados que viveram desde a metade do século XVI até meados do XVII, Lucinge elaborou suas considerações sobre a história pautado por uma experiência de ação política que tornava evidente o caráter pragmático dos estudos históricos; a questão do governo dos Estados colocada como objeto privilegiado das reflexões historiográficas. Segundo alguns estudiosos de sua obra, o livro sobre a leitura da história assume, por conseguinte, um teor eminentemente autobiográfico. Michael Heath sugeriu a influência, nesse sentido, dos Essais de Michel de Montaigne e Olivier Zegna Rata acredita que o La manière é uma espécie de testamento público de Lucinge, onde se evidencia uma experiência tateante da história. ${ }^{35}$ Admirador, como muitos à época, de

33 Ver: HUPPERT, George. The idea of perfect history. Historical erudition and historical philosophy in Renaissance France. Chicago: Urbana, 1970; e KELLEY, Donald. Historia Integra: Francois Baudouin and his Conception of History. Journal of the History of ldeas, vol.25, n.1, 1964.

34 LUCINGE, René de. La manière de lire l'histoire. Édition critique par Michael J. Heath. Genève: Droz, 1993

35 Ver: HEATH, Michael J. Introduction. In: LUCINGE, René de. La manière de lire I'histoire ...; e RATA, Olivier Zegna. René de Lucinge entre l'écriture et l'histoire. Genève: Librairie Dtoz, 1993. 
Políbio, encarava, todavia, alguns autores modernos com tendo realizado mais plenamente os desígnios da história. Maquiavel e Guicciardini eramIhe autores caros, os quais ensinavam a história como lição de realismo político.

Desde o começo, Lucinge ressalta que a singularidade de sua abordagem sobre a história reside justamente no fato de tomá-la como objeto de reflexão pelo viés da leitura. Nesse sentido, além de ensinamentos morais fornecidos pelo registro dos acontecimentos memoráveis do passado, o estudo da história pode conceder ao seu leitor a possibilidade de encontrar nela elementos para sua própria prática retórica, algo que remete ao próprio conceito ciceroniano de história, já que ela "enriquece o orador sobre as mesmas matérias que ele deve tratar, por meio de exemplos que ele pode recolher nos livros" ${ }^{36}$ Isto é, a leitura fornece também, além de exemplos de conduta prática, objetos sobre os quais é possível discursar ou fundamentar os discursos. Assim, duas são as formas principais de se ler a história: aquela ensinada pelos mestres e aquela descoberta, um pouco ao acaso, pela leitura solitária. De qualquer forma, para que a leitura seja de fato proveitosa, Lucing sugere ser fundamental que durante ela o plano da oralidade seja valorizado: no primeiro caso, ouve-se o mestre, o que torna assimilável o conteúdo transmitido; no segundo, a leitura em voz alta tende a ser apreensível de maneira mais eficaz que a leitura silenciosa. Nas palavras do autor, "a viva voz grava melhor aquilo que entra pelos nossos ouvidos na virtude retentiva da alma, sobretudo quando um douto pulmão a entoa: viva vox magis afficit [a viva voz tem muito mais força], dizem os sábios". ${ }^{37}$

Dessa maneira, se é louvável o estudioso que, ao ler livros de história, se ocupa em estudá-los com atenção, tomando notas cuidadosas daquilo que considera importante no texto lido, há um perigo notório em relegar ao papel e a esta outra escrita (das anotações) um lugar preponderante no entendimento. "Escrever primeiro as coisas memoráveis que nós lemos nos livros, isto as insinua, de início, de forma suficientemente forte em nossa memória; mas se nós depositamos nisso toda nossa confiança, reside aí o abuso, quando nós dobramos com os nossos papéis o estudo e o cuidado de deles nos relembrarmos" ${ }^{38} \mathrm{~A}$ postura é conhecida e remonta à desconfiança que Platão mantinha com relação à escrita, encarada por ele como um pharmacon, no caso, um veneno para a memória. ${ }^{39}$ Antes dos olhos, portanto, os ouvidos são os elementos por excelência da leitura. Mas não

36 LUCINGE, René de. La manière de lire l'histoire, p.57. Sobre a concepção retórica de história em Cícero, remeto a TEIXEIRA, Felipe Charbel. Uma construção de fatos e palavras: Cícero e a concepção retórica da história. Varia História, Belo Horizonte, vol.24, n.40, p.551-568, 2008.

37 LUCINGE, René de. La manière de lire l'histoire, p.73.

38 LUCINGE, René de. La manière de lire l'histoire, p.76.

39 Ver: GAGNEBIN, Jeanne Marie. Morte da memória, memória da morte: da escrita em Platão. In: Sete aulas sobre linguagem, memória e história. Rio de Janeiro: Imago, 1997. 
apenas isso, pois o que na realidade Lucinge defende é a idéia de que a ars historica pode ser compreendida também, sob o viés da leitura, como uma ars memoriae, uma arte da lembrança como técnica de imprimir lugares e imagens na memória, fornecendo ao orador uma estrutura segura para a defesa de seus argumentos. ${ }^{40}$

Se a leitura em voz alta se constitui como um procedimento mnemônico privilegiado nas considerações de Lucinge, não menos importante é o aspecto crítico que deve assumir o leitor diante do texto. $O$ adequado seria que ele conhecesse pormenorizadamente tanto o autor, quanto o tema sobre o qual ele escreve, além das normas corretas da linguagem, para uma boa avaliação das histórias lidas. O livro de história é objeto de uma disputa, de um confronto para o qual o leitor deve se mostrar preparado. Como ele mesmo coloca, "é preciso tornar-se inimigo do autor durante a leitura" ${ }^{41}$ Trata-se, todavia, de uma batalha travada com método, pois se o caso é, por exemplo, o de decidir entre versões distintas para um mesmo fato, seja ele antigo ou contemporâneo ao historiador que o narra, "é preciso que a alma se dispa de todo interesse, que ela lapide sua eficácia, que ela julgue de forma severa, sem defender um para desfavorecer o outro, sobretudo quando eles debatem sobre um ponto sensível onde se funda a verdade da controvérsia". ${ }^{42}$

Enfim, Lucinge situa com linhas claras o lugar do leitor no processo cognitivo de produção de legitimidade dos relatos históricos, legitimidade que torna possível, nesse sentido, encontrar ensinamentos na história narrada. No limite, ler bem um autor não significa apenas desvelar em seu texto uma verdade, mas sim saber tirar dele uma lição. Este homem de letras que diz ter começado suas experiências de leitura com romances escritos em língua vulgar, alimentou durante sua vida um reconhecido anseio pelo registro verdadeiro, recusando as meias verdades das fábulas e abandonando por vez as tolices que incitavam apenas o encanto fugidio. Tal o sentido pessoal com que dota seu texto, e a razão pela qual considerou divulgar para outros, mais dos que instruí-los, os caminhos que percorreu quando se propôs a aprender com a história.

Das contribuições de Lucinge, podemos, então, encaminhar o olhar para o século XVI, momento em que as considerações sobre a leitura da história fundaram um gênero discursivo, as artes historicae. Aqui, o breve texto de Thomas Blundeville, publicado em inglês no ano de 1575, e explicitamente inspirado nas obras de alguns eruditos italianos que the foram contemporâneos, nomeadamente Francesco Patrizi e Acontio Tridentino

40 Ver sobre as artes da memória, YATES, Frances. The art of memory. Chicago: The University of Chicago Press, 1966.

41 LUCINGE, René de. La manière de lire l'histoire, p.97.

42 LUCINGE, René de. La manière de lire l'histoire, p.116. 
(Giacomo Aconcio), é um desses exemplos a ser mencionado mais como ilustração do que pela importância de suas considerações. O título é The true order and method of wryting and reading histories. ${ }^{43}$

Para Blundeville, a leitura deve ser pensada como algo além do simples divertimento, como algo capaz de criar as condições para se elaborar um julgamento e um conhecimento que orientem na realização das ações privadas, bem como fornecer conselhos, marcados pela prudência na condução dos negócios públicos, sejam eles relativos à guerra ou à paz. ${ }^{44}$ Mas o dado significativo do livro é sua inspiração em eruditos italianos, o que demonstra um certo nível de circulação das idéias voltadas para a escrita e para a leitura da história a partir, sobretudo dos anos 1550, quando, inclusive, uma importante coletânea destes textos é organizada. Como afirma Anthony Grafton, "o gênero das Artes historicae cresceu de profundas raízes no pensamento antigo e do século $X V$, recebeu uma forma clara em meados do século XVI, assumindo formas canônicas entre os anos 1576 e 1579, quando o jurista Johannes Wolf publicou sua influente antologia, a Artis historicae penus". ${ }^{45}$

Dentre os textos mais relevantes deste contexto, o livro de Jean Bodin ocupa um lugar de destaque. Em 1566 é publicado o Methodus ad facilem historiarum cognitionem, "essa bagunçada, mal-intitulada obra-prima da geografia histórica", segundo as palavras de Grafton. Da ampla gama de interesses que inspirou o jurista francês, os quais passam por questões de direito universal e de demonologia, destaco aqui alguns breves comentários sobre a leitura da história. ${ }^{46}$ Segundo Bodin, o propósito fundamental das suas preocupações é "recolher as flores da história colhendo-lhe os frutos mais doces". ${ }^{47} \mathrm{~A}$ intenção que sustenta este propósito é menos, de sua parte, estabelecer os critérios para se escrever a história, e sim encontrar meio de perceber a utilidade do estudo da história para sua prática jurídica. Não é demais lembrar que, dez anos após a publicação do Methodus,

43 BLUNDEVILLE, Thomas. The true order and method of wryting and reading histories. London: Vvillyam Seres, 1574 (sigo a edição fac-similar, Amsterdam: Walter J. Johnson, 1979). O título completo é The true order and method of wryting and reading htstories, according to the precepts of Franciso Patricio, and Accontio Tridentino, two Italian writers, no lesse plainly than briefly, set forth in our vulgar speach, to the great profite an commoditye of all those that delight in Hystories. By Thomas Blundeuill of Newton Flotman in Norfolke. Ver ainda KAMPS, Ivo. The Writing of History in Shakespeare's England. In: DUTTON, Richard; HOWARD, Jean E. (eds.) A companion to Shakespeare's works. Volume II: the histories. Oxford: Wiley-Blackwell, 2003.

44 Na dedicatória ao "nobre" Erle of Leycester, Blundeville afirma sobre a leitura da história que "not as many doe, to passe away the tyme, but to gather thereof such iudgement and knowledge as you may therby be the more able, as well to direct your priuate actions, as to giue Counsell lyke a most prudent Counseller in publyke causes, be it matters of warre, or peace". BLUNDEVILLE, Thomas. The true order and method of wryting and reading histories, edição não paginada.

45 GRAFTON, Anthony. What was history?, p.21

46 Sobre Bodin, desenvolvi mais longamente estas considerações na palestra "Como se deve ler a história: Jean Bodin e o método para a fácil compreensão da história", proferida durante o $3^{\circ}$ Seminário Nacional de História da Historiografia, realizado em Mariana, agosto de 2009. O texto será publicado em breve no livro organizado a partir do evento.

47 Sigo a edição BODIN, Jean. La méthode de l'histoire. In: Ouvres philosophiques de Jean Bodin. Texte établi, traduit et publié par Pierre Mesnard. Paris: PUF, 1951, p.273. 
Bodin apresentou ao público aquela que viria a se tornar sua obra mais conhecida: Les six livres de la République. Donald Kelley e George Huppert, quase que simultaneamente, já haviam indicado a íntima relação, justamente para o contexto quinhentista francês, entre jurisprudência e história. ${ }^{48}$ Antes deles, Julian Franklin, em seu importante estudo sobre a obra de Bodin, situou ainda outra dimensão relevante dos debates em torno dos quais o gênero ars historica emergiu: o desafio colocado pelo pirronismo histórico que encontrou expressão, por exemplo, na obra de Cornelius Agrippa, publicada primeiramente em 1531, sendo traduzida para o francês cerca de meio século depois: Declamation sur l'incertitude, vanité et abus des sciences.

Nesse sentido, autores como o teólogo da Escola de Salamanca Melchior Cano e o jurista francês François Baudouin engendraram uma reação considerável contra a descrença em relação à confiabilidade dos textos históricos, reação que, segundo Franklin, ganhou em consistência justamente com o tratado de Bodin. ${ }^{49}$ Para o estudioso, o livro de 1566 seria o primeiro a sistematizar de forma mais coerente uma doutrina de criticismo interno, ou seja, regras para a verificação das asserções historiográficas. No limite, o método para a fácil compreensão da história equivale a uma arte de leitura da historiografia. Em que pese o teor da afirmação de Franklin, parece-me que a postura de Grafton se encontra mais de acordo com o livro de Bodin: uma obra confusa, extensa em demasia e com um título uma tanto distante dos resultados efetivos. De qualquer forma, uma obra cuja relevância não poderia deixar de ser mencionada nesta apresentação sumária.

Para não me alongar mais do que o necessário, dela menciono rapidamente alguns breves instantes que evidenciam o lugar do autor como leitor da história. Segundo Bodin, o mesmo método que se costuma seguir nas ciências, deve ser seguido na história, afinal, "não é suficiente acumular em si uma pilha de historiadores, é necessário ainda saber como utilizar cada um, em que ordem e de qual maneira é conveniente o ler". ${ }^{50} \mathrm{~A}$ metáfora de que ele se vale em seu argumento é significativa: da mesma forma como num banquete aprecia-se os mais diversos temperos, mas cuja cominação desregrada pode redundar num sabor pouco aprazível, a confusão no ordenamento das histórias pode engendrar equívocos indesejáveis. Convém ao bom leitor ler os textos, em primeiro lugar, na ordem cronológica em que se colocam. Começar pelo último e terminar pelo intermediário prejudica

48 HUPPERT, George. The idea of perfect history. Erudition and historical philosophy in Renaissance France. Chicago: Urbana, 1970; KELLEY, Donald R. Foundations of modern historical scholarship. Language, law, and history in the French Renaissance. New York: Columbia University Press. 1970.

49 FRANKLIN, Julian H. Jean Bodin and the Sixteenth-century revolution in the methodology of law and history. New York: Columbia University Press, 1963.

50 BODIN, Jean. La méthode de l'histoire, p.283. 
não apenas o entendimento, mas compromete igualmente a capacidade de se fundar na memória os seus conteúdos.

Aliado ao bom ordenamento das histórias, faz-se necessário uma espécie de resguardo crítico, repetido posteriormente por não poucos autores como foi visto. Nas palavras do autor, "segue-se, então, que para clarear a verdade histórica, é preciso não apenas escolher com cuidado suas fontes, mas também não esquecer o sábio aviso de Aristóteles segundo o qual, ao se ler a história não convém se mostrar muito crédulo nem totalmente cético. Pois se nós acreditamos em todos os autores sobre todas as coisas, pode acontecer muito recorrentemente de se tomar o verdadeiro pelo falso e, com isso, fracassar lamentavelmente na gestão dos negócios públicos; mas se, pelo contrário, nós recusamos toda a confiança na história, não retiramos dela nenhum fruto". Resulta que, para Bodin, "o prudente leitor da história manterá uma justa medida entre estes dois defeitos, dos quais um provém da vaidade e o outro se origina da insensatez; ele se contentará de fazer uma escolha minuciosa para não conservar senão as melhores fontes e de não projetar sobre o fato o menor julgamento antes de estar a par dos modos e do gênio do historiador". ${ }^{51}$ O jurista situa esta questão como um problema de amplitude social, pois a justiça no julgamento dos escritores impõe consequências importantes para a res publica. Por isso, o trabalho deste leitor é colocado num plano de extrema complexidade, pois o ideal seria que ele conhecesse muito bem tanto a prática da história quanto a condução dos assuntos públicos. Apenas neste quase todas as potencialidades da história poderiam assumir sua verdadeira relevância.

\section{VII.}

Enfim, neste vasto e lacunar panorama que perpassa pouco mais de quatro séculos, seguindo desde a emergência de um gênero histórico que encontrou em Jean Bodin um de seus mais notórios praticantes, até as recentes retomadas deste corpus documental como objeto de estudo para a compreensão da história da historiografia moderna, trabalho feito de forma lapidar por Anthony Grafton, um ponto espero ter podido sustentar: a significativa constância desta preocupação com as diferentes formas de leitura da história. As consequências teóricas de tudo isso merecem um desenvolvimento mais aprofundado. Para o momento, basta apenas indicar uma de suas possibilidades mais evidentes: levar em consideração que, ao se falar em escrita da história, não se deve perder de vista que esta história também é lida e que o ato de leitura ali implicado é parte constitutiva

51 BODIN, Jean. La méthode de l'histoire, p.294. 
do que se pode chamar conhecimento histórico. Uma evidência que nem sempre é levada em consideração. Talvez porque apenas o esforço de se compreender como a história se escreve já demande um volume de trabalho considerável. Mas talvez, também, a indagação sobre como a história deve ser lida pode lançar luz e contribuir para uma compreensão mais ampla do trabalho dos historiadores, levando-se em conta, quase que ao pé da letra, uma das brilhantes contribuições de Paul Veyne: "um livro de história não é, na realidade, o que aparenta ser". ${ }^{2}$ 